\title{
Kekasaran permukaan pada pemesinan frais mikro Ti 6Al- 4V ELI (extra low intertitial)
}

\author{
Gusri Akhyar Ibrahim ${ }^{1 *}$, Endra Saputra², Suryadiwansa Harun³, Eko Agus \\ Supriyanto4, Armulani Patihawa ${ }^{5}$
}

\author{
Jurusan Teknik Mesin, Fakultas Teknik, Universitas Lampung ${ }^{1,3}$ \\ Prodi Magister Teknik Mesin, Fakultas Teknik, Universitas Lampung ${ }^{2}$ \\ Prodi Teknik Mesin, Fakultas Teknik, Universitas Lampung ${ }^{4,5}$ \\ JI. Prof. Sumantri Brojonegoro No.1 Bandar Lampung 35145, Lampung, Indonesia \\ Email: gusri.akhyar@eng.unila.ac.id'1 ,endranidda83@gmail.com², \\ Suryadiwansa.harun@eng.unila.ac.id ${ }^{3}$, Bajang4@gmail.com ${ }^{4}$, \\ Armulani.pati.hawa019@gmail.com ${ }^{5}$
}

\begin{abstract}
One of the ingredients that are popular now is titanium, but titanium is a material that is difficult to process using conventional milling machining because of the poor thermal conductivity of the material so that the high-temperature machining process produced in the cutting zone causes plastic deformation in cutting tools and increased chemical reactivity in titanium. High-speed micro-milling machining can be used for micro machining of hard metals or alloys that are difficult to achieve at low speeds. Micro milling machining in titanium material 6Al-4V ELI with variations in milling tool diameter 1 and $2 \mathrm{~mm}$, spindle speed 10.000 and $15.000 \mathrm{rpm}$, feed 0,001 and 0,005 mm/rev, depth of cut 100 and $150 \mu \mathrm{m}$, which then do data processing using the method taguchi full factorial and theoretical analysis. The results showed that the diameter of the tool and into the depth of cut the most effect on surface roughness, the greater the tool diameter of the milling produced a smaller roughness value, this is inversely proportional to the depth of the cut. The lowest roughness value is 0,26 and the highest roughness value is 0,9.
\end{abstract}

Keywords: Micro milling machining, titanium 6Al-4V ELI, surface roughness.

\begin{abstract}
Abstrak
Salah satu bahan yang populer saat ini adalah titanium, tetapi titanium adalah bahan yang sulit untuk diproses menggunakan permesinan frais konvensional karena konduktivitas termal yang buruk dari bahan tersebut sehingga proses permesinan mengakibatkan suhu tinggi yang diproduksi di zona pemotongan menyebabkan deformasi plastik pada alat pemotong dan peningkatan reaktivitas kimia pada titanium. Pemesinan mikro berkecepatan tinggi dapat digunakan untuk pemesinan mikro logam keras atau paduan yang sulit dicapai pada kecepatan rendah. Pemesinan mikro milling pada bahan titanium 6Al-4V ELI dengan variasi diameter pahat 1 dan $2 \mathrm{~mm}$, kecepatan spindle 10.000 dan $15.000 \mathrm{rpm}$, feed 0,001 dan $0,005 \mathrm{~mm} /$ putaran, kedalaman potong 100 dan $150 \mu \mathrm{m}$, yang kemudian melakukan pemrosesan data menggunakan metode taguchi analisis faktorial dan analisa teoritis. Hasil penelitian menunjukkan bahwa diameter pahat dan kedalam potong memiliki efek paling besar pada kekasaran permukaan, semakin besar diameter pahat frais menghasilkan nilai kekasaran yang lebih kecil, ini berbanding terbalik dengan kedalaman pemotongan. Nilai kekasaran terendah adalah 0,26 dan nilai kekasaran tertinggi adalah 0,9.

Kata kunci: Pemesinan fais mikro, titanium 6Al-4V ELI, kekasaran permukaan.

\section{Pendahuluan}

Salah satu bahan yang paling populer saat ini adalah titanium. Titanium

adalah bahan yang banyak digunakan di bidang industri, penerbangan, biomedis, elektronik dan benda benda mikrokopis
\end{abstract}


lainya. Titanium juga merupakan logam yang sangat akrab dengan kehidupan manusia, banyak orang tahu bahwa titanium dapat digunakan dalam perhiasan, elekronik, alat kedokteran, dan produk lainya yang membutuhkan kekuatan bahan $[1,14]$.

Titanium juga merupakan logam yang sangat atraktif karena merupakan logam yang ringan tetapi mempunyai properti yang tangguh. Dalam bidang industri, titanium digunakan sebagai komponen untuk konstruksi pesawat, sistem pipa pada industri petrokimia, kilang minyak lepas pantai, dan alat olah raga. Dalam bidang kesehatan, titanium juga digunakan sebagai tulang buatan atau implan karena sifatnya yang bio kompatibel [2].

Akan tetapi, karakteristik titanium mudah bereaksi dengan material pahat potong sehingga cenderung membentuk build-up-edge dan melekat pada permukaan pahat potong [3, 13]. Konduktifitas thermal titanium yang rendah menyebabkan kerusakan permukaan pada bahan yang dipotong, sehingga merusak kualitas permukaan, adanya abrasi dan kerusakan mikrostruktur. Oleh karena itu titanium dikategorikan sebagai bahan yang sulit dimesin.

Konduktifitas thermal paduan titaniun yang rendah akan meningkatkan suhu pada ujung pahat potong yang mengakibatkan kegagalan pahat secara cepat, penyerpihan pada bagian ujung pahat potong ini menghasilkan kondisi permukaan bahan yang dimesin menjadi rusak, yang ditandai dengan permukaan yang kasar dan tidak seragam.

Hal ini tidak hanya menyebabkan nilai kekasaran permukaan yang tinggi, akan tetapi juga menyebabkan kerusakan mikrostruktur, hal ini juga berkontribusi terhadap kerusahan permukaan [3]. Kekasaran permukaan merupakan suatu hal yang sangat penting bagi suatu material. Hal ini dikarenakan material yang nantinya akan dijadikan suatu komponen harus memiliki suatu nilai kekasaran tertentu agar dapat sesuai dengan fungsi komponennya [4].

Ganguli dan kapoor [5] Mengatakan bahwa titanium dianggap bahan yang sulit diproses menggunakan pemesinan frais konvensional karena konduktivitas termal bahan yang buruk sehingga pada proses pemesinan dengan suhu tinggi yang dihasilkan di zona pemotongan menyebabkan deformasi plastis pada alat potong dan peningkatan reaktivitas kimia pada titanium. Tantangan dalam proses pembuatan micro parts untuk alat kesehatan pada pemesinan dengan material titanium terutama adalah sulitnya paduan titanium dimesin. Micro milling machining adalah proses pemesinan yang umum digunakan dalam produksi micro parts [6].

Karena produk micro parts sangat riskan terhadap gesekan, bahkan kekuatan kecil pun bisa menyebabkannya bencana kegagalan produk. Micro milling machining dengan kecepatan tinggi bisa digunakan untuk mengatasi masalah ini, karena beban chip yang lebih rendah pada tingkat kecepatan rotasi yang lebih tinggi, maka dari itu micro milling machining berkecepatan tinggi bisa digunakan untuk micro machining dari logam keras atau paduan yang sulit dicapai pada kecepatan rendah [7].

Sekarang micro milling kecepatan tinggi semakin populer karena mempunyai ketelitian dan permukaan akhir yang baik. Maka penelitian pada proses micro machining dengan material titanium semakin diminati.

\section{Tinjauan Pustaka}

\section{Pemesinan frais mikro (micro milling machining)}

Micro machining adalah proses pemesinan dimana parameter alat dan komponen atau parameter pemotongan ada pada kisaran mikrometer. Dengan demikian micro milling dapat diartikan juga sebagai mesin milling atau mesin perkakas dimana parameter alat dan komponen atau parameter pemotongan ada 
pada kisaran micrometer [6]. Seperti yang dikatakan Bajpai [8], bahwa Micro milling adalah proses pemesinan mekanis yang umum digunakan dalam produksi fitur mikroskopis. Mikrotool memiliki kekakuan yang sangat rendah dan bahkan kekuatan kecil pun bisa menyebabkannya bencana kegagalan alat, Micro machining dengan kecepatan tinggi bisa digunakan untuk mengatasi masalah ini karena beban chip yang lebih rendah pada tingkat kecepatan rotasi yang lebih tinggi. Akibatnya, micro milling berkecepatan tinggi bisa digunakan untuk micro machining dari logam keras atau paduan yang sulit dicapai pada kecepatan rendah. Sekarang micro milling kecepatan tinggi semakin populer karena mempunyai ketelitian dan permukaan akhir yang baik.

Dalam banyak kasus, produk mesin tidak perlu proses finishing tambahan. Namun, tingkat kekasaran dan pembentukan burr di proses pemesinan micro milling adalah masalah yang paling penting. Menghilangkan burr ukuran mikro sangat sulit dalam proses pemesinan micro milling. Maka penelitian ini difokuskan pada kekasaran permukaan dan pembentukan burr bahan dalam kecepatan tinggi micro milling untuk mendapatkan hasil yang baik [16]. Mesin frais mikro menggunakan kendali CNC (Computer Numerically Controlled) dan hampir semuanya adalah mesin frais vertikal. Mesin CNC akan bergerak secara otomatis setelah program kerjanya dimasukkan ke komputer yang telah dihubungkan ke mesin tersebut.

\section{Kekasaran permukaan}

Kekasaran permukaan dibedakan menjadi dua bentuk, diantaranya:

a. Ideal Surface Roughness

Yaitu kekasaran ideal yang dapat dicapai dalam suatu proses permesinan degan kondisi ideal.

b. Natural Surface Roughness

Yaitu kekasaran alamiah yang terbentuk dalam proses permesinan karena adanya beberapa faktor yang mempengaruhi proses permesinan diantaranya:
1. Keahlian operator

2. Getaran yang terjadi pada mesin

3. Ketidak teraturan feed mechanism

4. Adanya cacat pada material

\section{Metode Penelitian}

\section{Bahan}

Adapun bahan yang digunakan dalam penelitan ini adalah paduan Titanium 6Al-4V- ELI, dengan diameter $20 \mathrm{~mm}$ dan Tebal $4 \mathrm{~mm}$ dengan ketebalan titanium yaitu $4 \mathrm{~mm}$. Dengan bahan yang telah tersedia diharapkan dapat menyelesaikan penelitian ini dengan hasil yang baik.

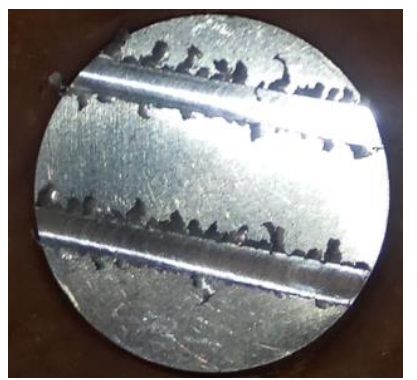

Gambar 1. Titanium 6Al-4V-ELI

\section{Alat}

Mesin Frais Micro Milling CNC merupakan mesin yang mampu melakukan banyak pekerjaan bila dibandingkan mesin perkakas yang lain. Sebagai hasilnya, mesin frais $\mathrm{CNC}$ mampu meratakan permukaan datar maupun berlekuk. Selain itu mesin ini juga berguna untuk menghaluskan atau meratakan benda kerja sesuai dengan dimensi yang dikehendaki [6, 12, 15]. Mesin Frais Micro Milling CNC ini dilengkapi dengan tiga axis travel dan spindel speed $20.000 \mathrm{rpm}$.

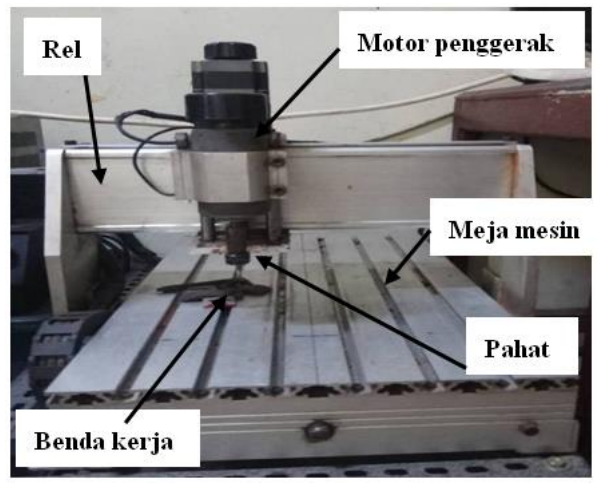

Gambar 2: Mesin CNC Micromilling 
Pada penelitian ini menggunakan pisau frais karbida [8], karena pisau frais karbida memiliki sifat yang tahan terhadap pengikisan (abrasi). Karbida merupakan material yang kaku di mana pisau frais karbida dapat dipakai untuk menyayat benda kerja yang terbuat dari material yang keras. Pisau frais karbida bisa dipakai pada kecepatan tinggi dengan keausan lebih sedikit sehingga dalam jangka panjang pisau frais dari material karbida lebih ekonomis. Pisau frais yang digunakan adalah pisau frais dengan jumlah flute 2 dan sudut $90^{\circ}$.

\section{Proses pengefraisan spesimen}

Dari kajian yang didapat, maka dipilihlah parameter-parameter pemesinan yang diharapkan dapat mendapatkan hasil yang terbaik [11], parameter parameter pengefraisan dapat dilihat di Tabel 1.

Tabel 1. Parameter penelitian

\begin{tabular}{|c|c|c|c|c|}
\hline $\begin{array}{l}\mathrm{N} \\
\mathrm{O}\end{array}$ & $\begin{array}{c}\text { Diamete } \\
\text { r pahat } \\
\text { Frais } \\
(\mathrm{mm})\end{array}$ & $\begin{array}{c}\text { Kecepata } \\
\text { n putaran } \\
\text { (n) } \\
(\mathrm{rpm})\end{array}$ & $\begin{array}{c}\text { Gerak } \\
\text { makan } \\
\text { (feeding)( } \\
\mathrm{f}) \\
(\mathrm{mm} / \mathrm{rev})\end{array}$ & $\begin{array}{c}\text { Kedalama } \\
\mathrm{n} \\
\text { potong }(\mathrm{p}) \\
(\mu \mathrm{m})\end{array}$ \\
\hline 1 & 1 & 10.000 & 0,001 & 100 \\
\hline 2 & 2 & 15.000 & 0,005 & 150 \\
\hline
\end{tabular}

Dengan menggunakan metode Taguchi full faktorial didapatkan proses pengambilan data sebanyak 16 sampel. Setelah proses pemesianan telah selesai maka selanjutnya mencari nilai kekasaran permukaan dengan menggunkan Surface roughness tester dan melihat permukaan material titanium 6Al-4V ELI dari hasil proses pemesinan menggunakan dengan cara uji SEM (Scanning electronic microscopy). Setelah semua data didapatkan maka kemudian barulah melakukan analisa dengan menggunkan metode Full Faktorial Design dan secara teoritis kemudian dilakukan pembahasan.

\section{Hasil dan Pembahasan}

Data hasil proses pengujian ini adalah berupa nilai kekasaran permukaan Titanium 6Al-4V ELI, dimana nilai kekasaran permukaan adalah varaibel tetap atau variabel respon dari pengujian. Dimana nilai kekasaran minimum dan juga nilai kekasaran maksimum yang dapat dilihat pada Gambar 3.

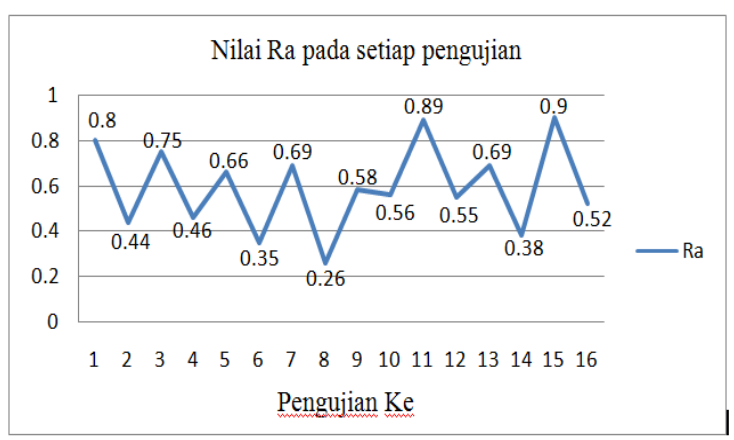

Gambar 3. Nilai Ra pada setiap pengujian

Dari Gambar 3. Dapat dilihat parameter uji yang menghasilkan nilai $\mathrm{Ra}$ minimum adalah pada parameter uji ke delapan dengan menggunakan diameter pahat $2 \mathrm{~mm}$, putaran spindel $15.000 \mathrm{rpm}$, feed $0,005 \mathrm{~mm} / \mathrm{rev}$ dan kedalaman potong $100 \mu \mathrm{m}$. Sedangkan parameter uji yang menghasilkan nilai kekasaran optimum adalah pada parameter uji ke limabelas dengan menggunakan diameter pahat 1 $\mathrm{mm}$, putaran spindel $15.000 \mathrm{rpm}$, feed $0,005 \mathrm{~mm} / \mathrm{rev}$ dan kedalaman potong 150 $\mu \mathrm{m}$. Adapun gambar permukaan dengan $\mathrm{Ra}$ minimal dan $\mathrm{Ra}$ optimal berdasarkan hasil dari pengujian dapat dilihat pada Gambar 4.

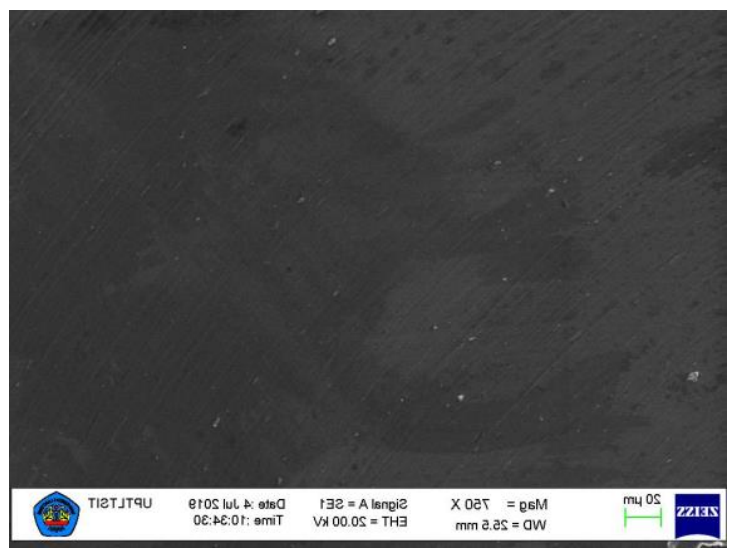

(a) 


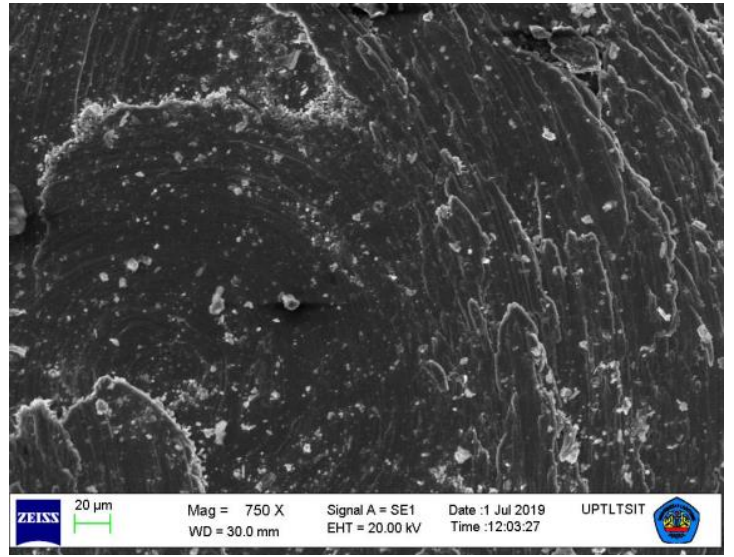

(b)

Gambar 4. Scanning electronic microscopy (SEM) (a) gambar permukaan menggunakan diameter pahat $1 \mathrm{~mm}$, putaran spindel $15.000 \mathrm{rpm}$, feed 0,005 $\mathrm{mm} / \mathrm{rev}$ dan kedalaman potong $150 \mu \mathrm{m}$ (b) gambar permukaan menggunakan diameter pahat $2 \mathrm{~mm}$, putaran spindel $15.000 \mathrm{rpm}$, feed $0,005 \mathrm{~mm} / \mathrm{rev}$ dan kedalaman potong $100 \mu \mathrm{m}$.

Gambar 4 Menunjukan hasil kualitas permukaan uji SEM dengan Ra minimal dan Ra optimal. Gambar 4 (a) terlihat nampak guratan gutaran dari sayatan pahat yang tidak konsisten, serta terdapat serpihan serpihan yang menempel pada permukaan selain itu juga terbentuk seperti sebuah ombak pada permukan yang menunjukkan bahwa kekasaran permukaan yang buruk. Selain itu banyak partikel chip yang menempel pada permukaan atau sering disebut dengan BUE. Partikelpartikel ini merupakan bagian tepi yang terlepas dan menempel ke permukaan bahan. Permukaan dengan $\mathrm{Ra}$ minimum gambar 4 (b) tidak banyak partikel chip yang menempel sehingga menghasilkan kualitas permukaan baik atau halus [16], nilai kekasaran permukaan sangat tergantung pada kadar pemakanan dan jari jari pahat potong [3].

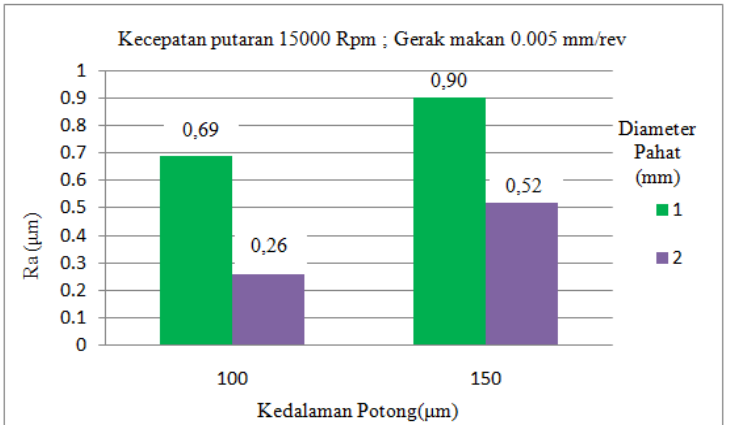

Gambar 5. Grafik kekasaran permukaan antara diameter pahat $1 \mathrm{~mm}$ dan $2 \mathrm{~mm}$ menggunakan kedalaman pemotongan 100 $\mu \mathrm{m}$ dan $150 \mu \mathrm{m}$, kecepatan putaran 15000 $\mathrm{rpm}$ dan gerak makan $0,005 \mathrm{~mm} / \mathrm{rev}$

Gambar 5 menujukkan bahwa pada kecepatan putaran $15000 \mathrm{rpm}$ dan gerak makan 0,005 $\mathrm{mm} / \mathrm{rev}$, menggunakan diameter pahat $2 \mathrm{~mm}$ menghasilkan nilai kekasaran permukaan yang lebih rendah dibandingkan dengan menggunakan pahat berdiameter $1 \mathrm{~mm}$. Pada kedalamam potong $100 \mu \mathrm{m}$, menggunakan pahat berdiameter $2 \mathrm{~mm}$ menurunkan nilai kekasaran permukan sebesar $62 \%$ dibandingkan dengan menggunakan diameter pahat $1 \mathrm{~mm}$. Hal tersebut juga terjadi pada kedalamam potong $150 \mu \mathrm{m}$, menggunakan pahat berdiameter $2 \mathrm{~mm}$ menurunkan nilai kekasaran permukan sebesar $42 \%$ dibandingkan dengan menggunakan diameter pahat $1 \mathrm{~mm}$.

Hal tersebut mungkin dikarenakan dengan menggunakan diameter pahat 2 mm menghasilkan kecepatan makan yang lebih tinggi dibandingkan dengan menggunakan diameter pahat $1 \mathrm{~mm}$ dengan demikian nilai keksaran permukaan menjadi lebih kecil atau baik, sedangkan pada kedalaman potong yang lebih besar akan mengakibatkan suhu yang semakin tinggi sewaktu proses pemesinan. Oleh karena itu hasil dari kekasaran permukaan dari proses pemesinan menjadi lebih tinggi atau buruk. 


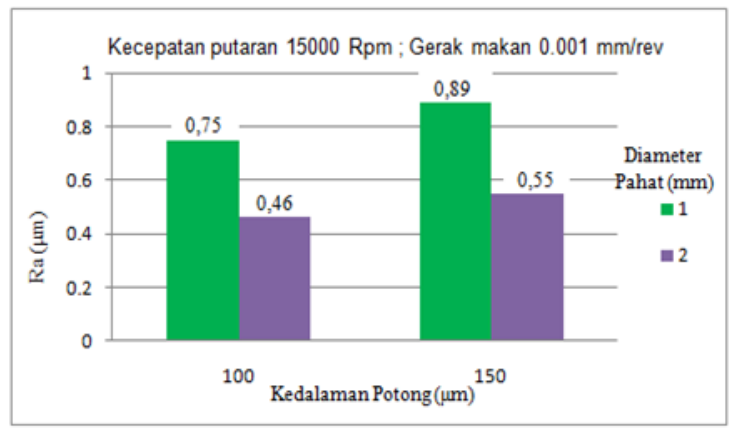

Gambar 6. Grafik kekasaran permukaan antara diameter pahat $1 \mathrm{~mm}$ dan $2 \mathrm{~mm}$, kedalaman potong $100 \mu \mathrm{m}$ dan $150 \mu \mathrm{m}$, kecepatan putaran $15000 \mathrm{rpm}$ dan gerak makan $0,001 \mathrm{~mm} / \mathrm{rev}$.

Gambar 6 menujukkan bahwa pada kecepatan putaran $15000 \mathrm{rpm}$ dan gerak makan $0,001 \mathrm{~mm} / \mathrm{rev}$, menggunakan diameter pahat $2 \mathrm{~mm}$ menghasilkan nilai kekasaran permukaan yang lebih rendah dibandingkan dengan menggunakan pahat berdiameter $1 \mathrm{~mm}$. Pada kedalamam potong $100 \mu \mathrm{m}$ menggunakan diameter pahat $2 \mathrm{~mm}$ menurunkan nilai kekasaran permukan sebesar $38 \%$ dibandingkan dengan menggunakan diameter pahat 1 $\mathrm{mm}$. Hal tersebut juga terjadi pada kedalamam potong $150 \mu \mathrm{m}$, menggunakan diameter pahat $2 \mathrm{~mm}$ menurunkan nilai kekasaran permukan sebesar $38 \%$ dibandingkan dengan menggunakan diameter pahat $1 \mathrm{~mm}$.

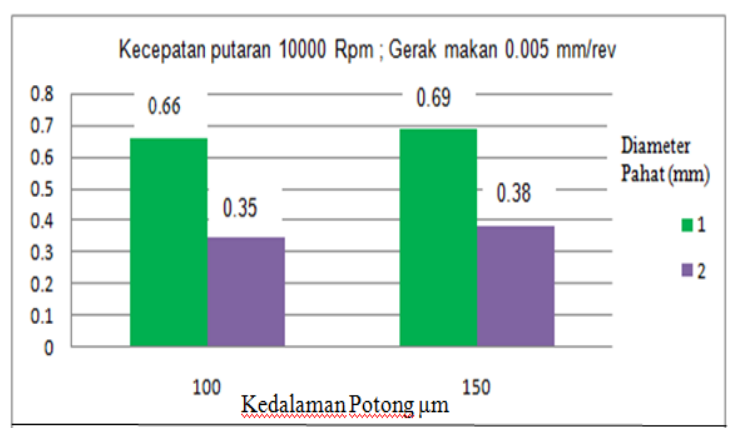

Gambar 7. Grafik kekasaran permukaan antara diameter pahat $1 \mathrm{~mm}$ dan $2 \mathrm{~mm}$ menggunakan kedalaman potong $100 \mu \mathrm{m}$ dan $150 \mu$ mdengan pada kecepatan putaran $10000 \mathrm{rpm}$ dan gerak makan 0,005 $\mathrm{mm} / \mathrm{rev}$.

Gambar 7 menujukkan bahwa pada kecepatan putaran 10000 rpm dan gerak makan 0,005 $\mathrm{mm} / \mathrm{rev}$, menggunakan diameter pahat $2 \mathrm{~mm}$ menghasilkan nilai kekasaran permukaan yang lebih rendah dibandingkan dengan menggunakan pahat berdiameter $1 \mathrm{~mm}$. Pada kedalamam potong $100 \mu \mathrm{m}$ menggunakan diameter pahat $2 \mathrm{~mm}$ menurunkan nilai kekasaran permukan sebesar $46 \%$ dibandingkan dengan menggunakan diameter pahat 1 $\mathrm{mm}$. Hal tersebut juga terjadi pada kedalamam potong $150 \mu \mathrm{m}$, menggunakan diameter pahat $2 \mathrm{~mm}$ menurunkan nilai kekasaran permukan sebesar $44 \%$ dibandingkan dengan menggunakan diameter pahat $1 \mathrm{~mm}$.

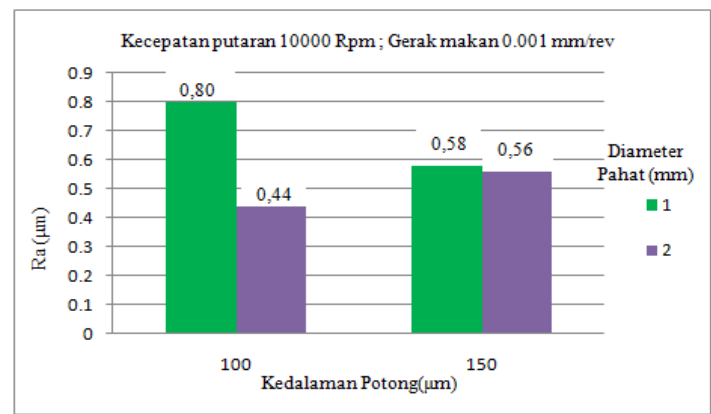

Gambar 8. Grafik kekasaran permukaan antara diameter pahat $1 \mathrm{~mm}$ dan $2 \mathrm{~mm}$ menggunakan kedalaman potong $100 \mu \mathrm{m}$ dan $150 \mu \mathrm{m}$ pada kecepatan putaran 10000 $\mathrm{rpm}$ dan gerak makan $0,001 \mathrm{~mm} / \mathrm{rev}$

Gambar 8 menujukkan bahwa pada kecepatan putaran $10000 \mathrm{rpm}$ dan gerak makan 0,001 $\mathrm{mm} / \mathrm{rev}$, menggunakan diameter pahat $2 \mathrm{~mm}$ menghasilkan nilai kekasaran permukaan yang lebih rendah dibandingkan dengan menggunakan pahat berdiameter $1 \mathrm{~mm}$. Pada kedalamam potong $100 \mu \mathrm{m}$ menggunakan diameter pahat $2 \mathrm{~mm}$ menurunkan nilai kekasaran permukan sebesar $45 \%$ dibandingkan dengan menggunakan diameter pahat 1 $\mathrm{mm}$. Hal tersebut juga terjadi pada kedalamam potong $150 \mu \mathrm{m}$, menggunakan diameter pahat $2 \mathrm{~mm}$ menurunkan nilai kekasaran permukan sebesar $3 \%$ dibandingkan dengan menggunakan diameter pahat $1 \mathrm{~mm}$.

\section{Kesimpulan}

Diameter pahat secara signifikan menurununkan nilai kekasaran permukaan. 
Nilai kekasaran minimum yaitu $0,26 \mu \mathrm{m}$ dengan menggunakan parameter pemesinan kecepatan spindel $15.000 \mathrm{rpm}$, gerak makan $0,005 \mathrm{~mm} / \mathrm{rev}$, kedalaman potong $100 \mu \mathrm{m}$, dan diameter pahat frais 2 $\mathrm{mm}$. Penurunan nilai kekasaran permukaan terbesar adalah sebesar $62 \%$ pada parameter kecepatan putaran $15000 \mathrm{rpm}$, gerak makan $0,005 \mathrm{~mm} / \mathrm{rev}$, kedalaman potong $100 \mu \mathrm{m}$ dengan diameter pahat 1 mm sebesar 0,69 $\mu \mathrm{m}$ dan diameter pahat 2 $\mathrm{mm}$ sebesar $0,26 \mu \mathrm{m}$ sehingga selisihnya $0,43 \mu \mathrm{m}$.

\section{Referensi}

[1]. Rifai, M., (2018), Analisis keausan pahat pada pemesinan bubut pada pahat putar modular (modular rotary tools) untuk material titanium 6Al4V ELI. Jurusan Teknik Mesin, Universitas Lampung, Bandar Lampung.

[2]. Josephine, M., Windajati, D.J., Djoko H., Santjojo, Abdurrouf., (2017), Pembentukan titanium nitrida (TiN) dengan proses nitriding pada titanium murni menggunakan plasma densitas tinggi ,Jurnal Rekayasa Mesin,v.8, n.2, pp. 83-90.

[3]. Ibrahim, G., A., (2014), Pengaruh pemesinan kering terhadap kekasaran dan kekerasan permukaan paduan titanium, Jurnal Mechanical, v.5, n.2, pp. 6-11.

[4]. Prasetyo, E. D., (2015), Analisis perbandingan metode pengujian kekasaran permukaan pada material komponen dan komposit - review, Jurnal Rekayasa Mesin,v.6, n.2, pp. 171-175.

[5]. Ganguli, S., Kapoor, S., G., (2016), Improving the performance of milling of titanium alloys using the atomization - based cutting fluid application system, Department of Mechanical Science and Engineering, University of Illinois, Urbana, IL, United States : Journal of Manufacturing Processes 29-36.
[6]. Tamborlin, M., O. Mewis, Jan, Ramos, Klaus, Schutzer, (2017), Iinfluence of cutting parameters in micro-millinf of moulds for microcomponents, Croatian Association of Production Engineering, Zagreb.

[7]. Zhu, Kunpeng, Xiaolong, Y., (2017), The monitoring of micro milling tool wear conditions by wear area estimation, Mechanical Systems and Signal Processing 80-91.

[8]. Bajpai, V., Remesh, K.S., Kushawaha, A.K., (2017), Burr formation and surface quality in high speed micromilling of titanium alloy (TI6AI4V), Indian Institute of Technology Bombay, India.

[9]. Embrijakto, R., D., (2018), Kajian Pemesinan Bor Material Magnesium Menggunakan Metode Taguchi, Fakultas Teknik mesin. Universitas lampung. Bandar Lampung.

[10]. Anang, A., (2015), Pengaruh kecepatan potong dan makan terhadap umur pahat pada pemesinan freis paduan magnesium, Jurnal Mechanical, v.6, n.1, pp. 28-35.

[11]. Triwibowo, S., Madya, W., (2015), Keausan alat potong (Tool Wear), PPPPTK BOE Malang.

[12]. Ardhy, Sanny, Gunawarman, Affi Jon., (2015), Perilaku korosi titanium dalam larutan modifikasi saliva buatan untuk aplikasi ortodontik, Jurusan Teknik Mesin, Universitas Andalas, Padang.

[13]. Uhlamann, E., Oberschmid, Kuche, Lowenstein, Winker., (2016), Effects of different cutting edge preparation methods on micro milling performance, Technische Universität Berlin, Pascalstrabe 8-9, 10587 Berlin, Germany.

[14]. Thepsonthi, T., and Ozel, T., (2012), Multi- Objective Process Optimization For Micro-end Milling of Ti-6Al-4V Titanium Alloy, Int J Adv Manuf Technol, London. 